\title{
Physical Activity Levels and Performance in Italian Adolescents with Cystic Fibrosis: A Multicenter Cross-sectional Study
}

Clizia Cazzarolli ${ }^{*}$, Gloria Tridello', Chiara Tartali², llaria Meneghelli ${ }^{1}$, Maria Antonietta Ciciretti ${ }^{3}$, Giulia Mamprin ${ }^{4}$, Patrizia Fanzaghi $^{5}$, Diletta Innocenti ${ }^{6}$, Francesca Grisorio ${ }^{3}$, Sara Tomezzoli' and Sonia Volpi ${ }^{1}$

${ }^{1}$ Centro Regionale Veneto per la Cura della Fibrosi Cistica, Azienda Ospedaliera Universitaria Integrata Verona, Italy

2U. O.C. Medicina Fisica e Riabilitazione, Azienda ULSS 9 Scaligera Verona, Italy

${ }^{3}$ Servizio di Supporto Fibrosi Cistica di Cerignola, P.O. "G. Tatarella" ASL Foggia, Italy

${ }^{4}$ Servizio di Supporto Fibrosi Cistica di Treviso-Presidio Ospedaliero di Treviso, Italy

${ }^{5}$ Centro Regionale per la Fibrosi Cistica-Azienda Ospedaliero Universitaria di Parma, Italy

${ }^{6}$ Centro Regionale per la Fibrosi Cistica-Ospedale Meyer Firenze, Italy

\begin{abstract}
The aim of this study was to compare physical performance in Italian adolescents with different habitual activity levels and to examine its relationship with peripheral muscle strength and quality of life.

At regular clinic visits in 5 cystic fibrosis (CF) Centres in Italy, 35 subjects performed spirometry, incremental shuttle walk test (ISWT), one-repetition maximum (1 RM) and completed the Habitual Activity Estimation Scale (HAES). Subjects were divided into two groups, based on activity levels derived from the HAES.

More active subjects achieved higher ISWT distance (ISWD) (1040.4 m vs.851.3 m, p=0.2) and described better body image perception $(75.7 \%$ vs. $66.7 \% \mathrm{p}=0.3)$ than subjects in the less active group, but these results did not reach a statistical significance. There was no correlation between ISWD, lung function and quality of life, but we observed a moderate correlation between ISWD and upper limb strength $(r=0.46)$.
\end{abstract}

Our data showed that more active subjects did not differ from less- active ones. Further studies should choose alternative tools to assess physical activity levels in order to detect the real engagement in vigorous activities, making it easier to compare and combine results and promote educational intervention.

Keywords: Cystic fibrosis; Adolescents; Habitual activity; Physical performance

\section{What is Known}

- Exercise participation improves clinical outcomes and prevents lung function decline.

- Adolescents with $\mathrm{CF}$ present a reduced participation in recreational and sportive activities.

\section{What is New}

- More active adolescents did not achieve higher distance in incremental shuttle walk test.

- Performance did not seem to be associated with lung function and strength.

Abbreviations: 1RM: One Repetition Maximum; ATS: American Thoracic Society; BMI: Body Mass Index; CF: Cystic Fibrosis; CFQ-R: Revised Cystic Fibrosis Questionnaire; COPD: Chronic Obstructive Pulmonary Disease; $\mathrm{FEV}_{1}$ : Forced Expiratory Volume in 1 Second; $\mathrm{FEF}_{25}$ ${ }_{75}$ : Forced Expiratory Flow At $25-75 \%$ of Forced Vital Capacity; HAES: Habitual Activity Estimation Scale; ISWD: Incremental Shuttle Walk Distance; ISWT: Incremental Shuttle Walk Test; PA : Physical Activity; QOL: Quality of Life; SA: Somewhat Active; SD: Standard Deviation; SI: Somewhat Inactive; TA: Total Activity; VA: Very Active; $\mathrm{V}^{\prime} \mathrm{O}_{2}$ peak: Peak Oxygen Uptake

\section{Background}

Cystic fibrosis (CF) is characterized by the progressive deterioration of lung function and reduction of exercise tolerance. For this reason, exercise is an important component in the care of subjects with CF [1,2].

A growing body of research has demonstrated that exercise training and physical activity (PA) are associated with decreased mortality [3], slower rate of decline in respiratory function $[4,5]$, higher bone mineral density [6], improved nutritional status and health-related quality of life [7].

Habitual PA refers to activity that is incorporated into daily life, is less structured than traditional exercise training and can encompass a wide range of intensity levels. A progressive decline in PA levels and exercise participation occurs during adolescence both in healthy subjects and youth with CF [7].

Williams and Stevens stated that children and adolescents with CF have a reduced ability to tolerate exercise [8]; this has serious implications for their well-being and quality of life (QOL) and limits their involvement in sports and recreational activities. Several studies investigated the PA of subjects with CF compared to healthy subjects; however, the results were mixed and different depending on the study method and the age group included.

Nixon et al. [9] found that children and adolescents who participated in very strenuous PA had a reduced aerobic fitness even with well-preserved lung function.

*Corresponding author: Clizia Cazzarolli, Centro Regionale Veneto per la Cura della Fibrosi Cistica, Azienda Ospedaliera Universitaria Integrata, Piazzale Stefan 1, 37126 Verona, Italy, Tel: +39 0458123162; E-mail: clizia.cazzarolli@aovr.veneto.it

Received November 06, 2017; Accepted November 09, 2017; Published November 16, 2017

Citation: Cazzarolli C, Tridello G, Tartali C, Meneghelli I, Antonietta Ciciretti IM et al. (2017) Physical Activity Levels and Performance in Italian Adolescents with Cystic Fibrosis: A Multicenter Cross-sectional Study. J Pulm Respir Med 7: 430 doi: 10.4172/2161-105X.1000430

Copyright: (c) 2017 Cazzarolli C, et al. This is an open-access article distributed under the terms of the Creative Commons Attribution License, which permits unrestricted use, distribution, and reproduction in any medium, provided the original author and source are credited. 
Others described no significant differences in PA to healthy peers $[2,7,10]$. Regarding pulmonary function, some authors reported that higher PA levels were associated with a slower rate of decline in $\mathrm{FEV}_{1}$, specifically in girls with CF $[5,11]$. Considering these findings and given that many adolescents fail to reach the recommended level of PA, there is the need to ensure that youth are meeting the PA guidelines recommended for optimal health outcomes. In Italy, the current standards of care are poorly and sporadically implemented nationally and there are no published data on their PA levels in association with physical performance. These data could encourage an improved evidence based exercise evaluation and the prescription of exercise training.

The purpose of this study was twofold. First, we aimed to compare physical performance in Italian adolescents with different habitual activity levels. Second, we aimed to determine the relation between activity levels with muscle strength, lung function and quality of life. The hypothesis was that the adolescents with CF that spend more than $50 \%$ of time awake engaged in moderate-vigorous activity in a typical weekday would perform better measurments of PA, strength and have better QOL $[12,13]$.

\section{Materials and Methods}

\section{Study design and participants}

This was a cross-sectional study that involved $5 \mathrm{CF}$ centres in Italy.

Adolescents with a confirmed diagnosis of $\mathrm{CF}$, aged between 12 and 18 years, were consecutively recruited from the paediatric $\mathrm{CF}$ out subject clinics at Cerignola (Foggia), Firenze, Parma, Treviso and Verona. Exclusion criteria were pulmonary exacerbation in the last two weeks, co-morbidities limiting mobilization, need of oxygen therapy or lung transplant recipient.

Ethics committees from Firenze, Foggia, Parma, Treviso and Verona approved the study protocol.

Written informed consent was obtained from each participant and from a parent or guardian if the adolescent was a minor.

\section{Measurements}

Anthropometric data: Height and weight were measured and a $\mathrm{z}$-score for body mass index percentiles was calculated according to Centers for Disease Control and Prevention 2000 Standards [14].

Pulmonary function testing: Spirometry was performed according to ATS technique [15]. Value was expressed as a percentage of the predicted value for height, gender and age.

Habitual activity: Subjects completed the Habitual Activity Estimation Scale (HAES) questionnaire for a typical weekday of the previous 2 week [16]. Percentage of time awake was documented in each of 4 activity categories: inactive (lying down), somewhat inactive (SI, sitting down), somewhat active (SA, walking) and very active (VA, those activities that make subject "breathe hard and sweat"). The use of wake-up and bedtimes as well as meal times and durations allowed the calculation of the total number of hours per day spent in each of the 4 categories. Total activity (TA) was calculated as SA+VA for each day.

For this study, habitual activity was expressed as the time when the study subject was awake and engaged in moderate-vigorous activity and recorded for a typical weekday. Subjects with a awake time of 25 percentile or more were classified as "active", whilst subjects active for less than 25 percentile of awake time were considered "less-active" $[12,13]$.
Physical performance: Performance was assessed using the Incremental Shuttle Walk Test (ISWT) that is a validated field test of exercise tolerance in CF in which participants walk $10 \mathrm{~m}$ lengths at progressively increasing paces [17]. The number of completed shuttles and ISWT distance (ISWD) recorded and used to express exercise tolerance.

Muscle strength: Measuring muscle strength consisted of a onerepetition maximum strength test (1 RM) $[18,19]$. The $1 \mathrm{RM}$ test is defined as the maximum weight lifted once during the performance of a standardised weight lifting exercise. The $1 \mathrm{RM}$ test involved two movements: elbow flexion and squat.

Quality of life: The Italian Revised CF Quality of Life Questionnaire (CFQ-R) was administered to assess the subject's quality of life. The CFQ- $R$ is a validated instrument for CF subjects that scores quality of life in twelve general and CF-specific domains. This study focused on six pre-defined exercise-related domains: physical functioning, emotional functioning, social functioning, body image perception, burden of treatment and respiratory wellness. Scores for each domain were expressed on a scale of $0-100$ [20].

Statistics sample size: Assuming that the difference between active and less-active group is comparable to the benefit obtained after an antibiotic treatment, we expect to detect a difference of 175 meters at the Incremental Shuttle Walk Test (ISWT) between the two groups [21]. To verify this hypothesis, a total of 30 subjects are needed, considering a standard deviation of 160 , two sided alpha equal to 0.05 , power $=80 \%$. Since that, questionnaire and tests are performed during the same day, no drop-out are expected.

Statistical analysis: The main characteristics of subjects were described reporting absolute and percent frequencies in case of categorical variables and median, range, mean and standard deviation (SD) for the continuous variables.

Primary endpoint: The physical performance was compared in the active and in less-active group by the Mann-Whitney test.

Difference in weight, height, BMI, pulmonary function testing (vital capacity, $\mathrm{FEV}_{1}$ and $\mathrm{FEF}_{25-75}$, expressed as a percentage of the predicted value for height, gender and age), muscle strength and QoL were investigated in the two groups as secondary endpoints: their differences were tested using the Chi square test or Fisher exact test in case of categorical variables, and the Mann-Whitney test in case of continuous variables. A p-value $<0.05$ was considered statistically significant.

All the analyses were performed by using the statistical software SAS (ver 9.4, SAS Institute Inc., Cary, NC, USA).

\section{Results}

\section{Demographics}

A total of 35 eligible subjects were included in the study: 18 males and 17 females, mean age at enrolment 15.4, range 11.8-18.7. Overall subjects showed normal lung function (mean $\mathrm{FEV}_{1} 82.0 \%$ predicted) and fairly good nutritional status (mean BMI percentile-for-age 34.8 \pm 26.8 ).

Main characteristics of subjects are presented in Table 1. Since that no major difference in demographic and clinical characteristics were observed between active and less-active population, the two groups could be considered comparable. Table 2 describes PA data in the two groups. 
Citation: Cazzarolli C, Tridello G, Tartali C, Meneghelli I, Antonietta Ciciretti IM, et al. (2017) Physical Activity Levels and Performance in Italian Adolescents with Cystic Fibrosis: A Multicenter Cross-sectional Study. J Pulm Respir Med 7: 430. doi: 10.4172/2161-105X.1000430

Page 3 of 5

\begin{tabular}{|c|c|c|c|c|}
\hline \multirow{2}{*}{ Characteristics } & \multirow{2}{*}{ All $\mathrm{N}=35$} & \multicolumn{2}{|c|}{ Activity level } & \multirow{2}{*}{$\mathbf{p}$} \\
\hline & & Active $\mathrm{N}=27$ & Less-active $\mathrm{N}=8$ & \\
\hline Gender (M/F) & $18 / 17$ & $13 / 14$ & $5 / 3$ & \\
\hline Age (yrs) & $15.4 \pm 1.9(11.8-18.7)$ & $15.4 \pm 2.0(11.8-18.7)$ & $15.1 \pm 1.5(13.0-16.8)$ & n.s. \\
\hline BMI \% for age & $34.8 \pm 26.8(0.3-89.6)$ & $35.2 \pm 24.7(2.63-76.8)$ & $33.1 \pm 34.7(0.26-89.6)$ & n.s. \\
\hline FEV1\% pred & $82.0 \pm 25.3(2.5-134)$ & $82.1 \pm 26.5(2.5-134)$ & $81.6 \pm 22.3(44-107)$ & n.s. \\
\hline FEF25-75\% pred & $65.5 \pm 29.8(12-116)$ & $68.8 \pm 29.7(12-116)$ & $54.6 \pm 29.5(19-95)$ & n.s. \\
\hline
\end{tabular}

Table 1: Demographic and clinical characteristics in the study measured by activity levels.

\begin{tabular}{|c|c|c|}
\hline \multirow{2}{*}{ Characteristics } & \multicolumn{2}{|c|}{ Activity level } \\
\cline { 2 - 3 } & Active N=27 & Less-active N=8 \\
\hline Total activity hours $\%$ of time awake that the subject is active & $4.7 \pm 1.1(2.8-6.4)$ & $33.3 \pm 7.5(20.3-42.8)$ \\
\hline Data are presented as $\mathrm{n}$ or mean \pm SD (range). & $62.4 \pm 13.9(39.7-83.4)$ \\
\hline
\end{tabular}

Table 2: Physical activity data.

\begin{tabular}{|c|c|c|c|c|}
\hline \multirow{2}{*}{ Characteristics } & \multirow{2}{*}{ All $\mathrm{N}=35$} & \multicolumn{2}{|c|}{ Activity level } & \multirow{2}{*}{$\mathbf{p}$} \\
\hline & & Active $\mathrm{N}=27$ & Less-active $\mathbf{N}=8$ & \\
\hline ISWT(distance-meters) & $997.1 \pm 314.5(520-1500)$ & $1040.4 \pm 336.4(520-1500)$ & $851.3 \pm 168.9(630.0-1100)$ & n.s. \\
\hline ISWT (level) & $11.4 \pm 2.3(8-15)$ & $11.7 \pm 2.5(8-15)$ & $10.6 \pm 1.2(9-12)$ & n.s. \\
\hline 1RM arms & $7.1 \pm 4.3(3-23.5)$ & $7.2 \pm 4.6(3-23.5)$ & $6.8 \pm 2.8(4-12)$ & n.s. \\
\hline 1RM legs & $39.8 \pm 20.8(5-89.5)$ & $40.3 \pm 21.8(5-89.5)$ & $38.2 \pm 17.9(15-62)$ & n.s. \\
\hline \multicolumn{5}{|l|}{ CFQ-R scores } \\
\hline Physical & $82.4 \pm 20.6(12.5-100)$ & $81.7 \pm 22.3(12.5-100)$ & $84.9 \pm 14.1(66.7-100)$ & n.s. \\
\hline ...Emotional & $78.4 \pm 19.6(20-100)$ & $79.4 \pm 20.3(20-100)$ & $74.8 \pm 17.9(46.7-100)$ & n.s. \\
\hline Social & $70.4 \pm 13.0(44.4-88.9)$ & $69.8 \pm 11.9(44.4-88.9)$ & $72.3 \pm 16.9(44.4-88.9)$ & n.s. \\
\hline Body image & $73.7 \pm 24.3(0100)$ & $75.7 \pm 24.7(0-100)$ & $66.7 \pm 23.0(33.3-100)$ & n.s. \\
\hline
\end{tabular}

Table 3: Secondary endpoints measured by activity levels.

\begin{tabular}{|c|c|c|}
\hline & Variable & Correlation coefficient $\mathbf{r}$ \\
\hline \multirow{3}{*}{ ISWD } & FEV1 & 0.37 \\
\cline { 2 - 4 } & FEV1\% pred & -0.05 \\
\cline { 2 - 4 } & 1RM arms & 0.03 \\
\cline { 2 - 4 } & 1RM legs & 0.46 \\
\hline
\end{tabular}

Table 4: Correlation between ISWD and pulmonary function in CF subjects.

\section{Primary endpoint}

Physical performance. The mean ISWD obtained was about $200 \mathrm{~m}$ higher in the active group $(1040.4 \mathrm{~m} \pm 336.4)$ respect to the less-active group $(851.3 \mathrm{~m} \pm 168.9)$, even this difference was statistically significant $(\mathrm{p}=0.2)$ (Figure 1)

\section{Secondary endpoints}

Muscle strength. The mean 1RM arms value was $7.2 \pm 4.6$ and $6.8 \pm$ 2.8 for the active and the less-active group, respectively; whilst the mean $1 \mathrm{RM}$ leg value was $40.3 \pm 21.8$ and $38.2 \pm 17.9$, respectively (Table 3 ).

\section{Quality of life}

A 9-point higher score was detected for the body image perception domain in the active group respect to the less-active one (75.7 \pm 24.7 $v s$. $66.7 \pm 23.0$ ): this difference is quite relevant, even if it does not reach the statistical significance.

Similar scores were obtained in the two groups for the remaining QoL domains: the physical functioning was $81.7 \pm 22.3$ vs. $84.9 \pm 14.1$; the emotional functioning was $79.4 \pm 20.3$ vs. $74.8 \pm 17.9$; the social functioning was $69.8 \pm 11.9 v s .72 .3 \pm 16.9$; the burden of treatment was

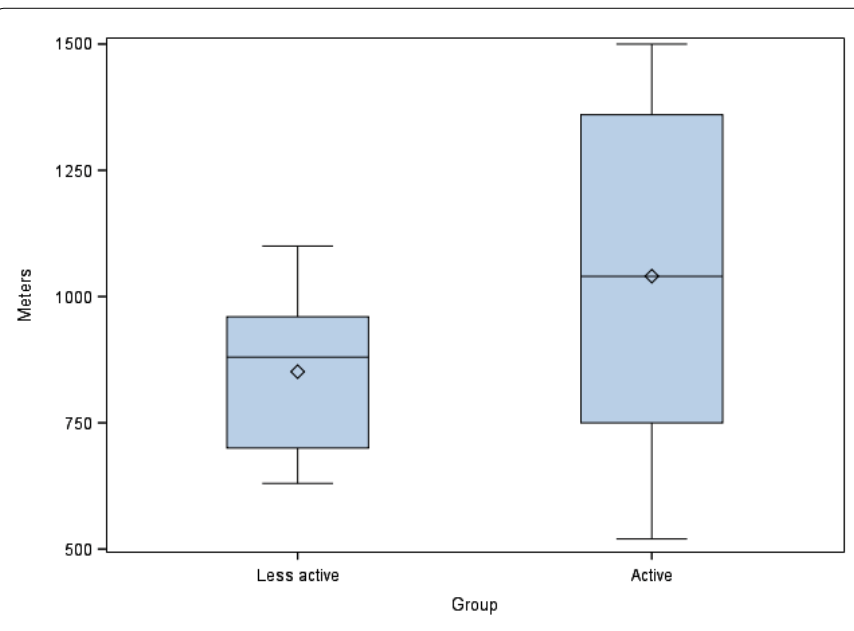

Figure 1: Physical performance between active group and less active group.

$53.5 \pm 17.4 v s .69 .4 \pm 26.4$; the respiratory function was $73.4 \pm 22.2 v s$. $87.8 \pm 5.1$, in the active and in the less-active group, respectively 
A moderate correlation was observed between 1RM arms and ISWD, $\mathrm{r}=0.46, \mathrm{p}=0.006$, whilst a mild correlation was found between the ISWD and respiratory functions, $\mathrm{r}=0.37, \mathrm{p}=0.03$ (Table 3 ).

\section{Discussion}

Few studies have examined the role that PA may play in determining subjects' exercise tolerance in adolescents with CF. While exercise training has been recommended for inclusion in CF routine therapy, issues such as the burden of disease and inadequate adherence have made it a challenge to incorporate into a treatment programme. For these reasons, PA remains underutilized and not always incorporated into routine CF management [8] despite it is recommended as part of the treatment regimen $\mathrm{CF}$ although objective methods have been scarcely used to monitor achievement of PA guidelines [10].

The available data on the relationship between habitual PA and measures of physical fitness is somewhat controversial. Nixon et al. [9] found no correlation between the reported time spent in vigorous activities and maximal oxygen uptake $\left(\mathrm{V}^{\prime} \mathrm{O}_{2}\right.$ peak) in 30 subjects aged 7-19 years. Schneidermann et al. [5] found no significant association between $\mathrm{V}^{\prime} \mathrm{O}_{2}$ peak and habitual PA. Controversially another author speculated that PA could be a significant, although relatively weak, predictor of $\mathrm{V}^{\prime} \mathrm{O}_{2}$ peak in $\mathrm{CF}$ [8]. The positive relationship between PA levels and aerobic fitness is supported by a recent study by Savi et al. [22]. Our results do not add more knowledge to published data. In fact we found that physical performance tend to be higher in the more active adolescents with CF, even if the difference between active and less-active group did not reach the statistically significance.

Regarding strength, previous studies looking the relationship between peripheral muscle strength and PA are limited. Selvadurai et al. [23] stated that despite normal lung function and good nutritional status, female athletes with CF had significantly lower anaerobic power and leg strength than healthy subjects supporting the hypothesis that strength seems to be reduced for intrinsic skeletal muscle defects and not for PA habits. Muscle strength is an important factor to consider when investigating exercise tolerance, and physical inactivity is probably the major contributor of peripheral muscle abnormalities in subjects with $\mathrm{CF}$ with mild-to-moderate phenotypes. However, the relative influence of additional factors (e.g. inflammation, metabolic abnormalities) probably increases with disease severity making specific and individualized interventions necessary in severe subjects.

Most of the studies examined only leg muscle strength [23-25]. In our study a moderate correlation was find between upper limb strength and ISWT. We found only a study that detected a reduced arm work capacity in CF but only in subjects with severe pulmonary impairment [26]. The role of arm strength on exercise performance should be further investigate to understand if upper limb strength could influence walking distance like in COPD [27].

In published studies, changes in reported PA were directly related to changes QoL scores. Hebestreit et al. [28] showed that in CF subjects $\mathrm{V}^{\prime} \mathrm{O}_{2}$ peak correlate positively with QOL. Cox et al. [4] reported higher scores in QoL by adult subjects with CF who performed $\geq 30$ minutes of moderate-vigorous PA daily compared to those who performed $<30$ minutes daily. In a cross-sectional study on children with CF, PA was found to correlate quite strongly with QOL [7]. In our study we found a 9-points higher body image perception in the more active group, even if no statistical significance were detected in difference of QOL scores between groups previous studies reported similar results [29]. Hommerding et al. [30] found no significant improvement in QoL domains after an education intervention of PA for children and adolescents with CF. Another study reported that QoL was associated with physical fitness and to a lesser extent with reported PA [28]. We can speculate that participation in PA could not directly increase QOL perception, but might improve subjects' self-esteem and consequently their adherence to exercise programs.

\section{Limitations}

First, the questionnaire used in this study was the HAES, the one with the most available data in literature. It currently represents an informed choice to measure physical activity via questionnaire and it could be useful to screen PA levels and generate discussion on PA patterns. A recent position statement suggested that questionnaires should not be used as primary outcome measures without fully assessing their clinometric properties [30]. In fact, assessing PA in adolescents using self- or parent-administered questionnaires has many limitations: they find it especially difficult to describe or quantify their PA levels and there is the risk for over reporting active habits. Accelerometers could provide minute-by-minute recording of $\mathrm{PA}$ and could therefore be used to objective quantify PA $[7,28]$.

There is a need for longer and objective monitoring PA and the use of intensity cut- points to obtain information on usual PA levels in adolescents with CF (including the comparison of weekend $v s$. weekday activity behaviour) and on how well these subjects comply with current guidelines.

Second, the criteria used to separate the participants into the active and less-active group are somewhat arbitrary.

Third, ISWT is not the gold standard in determining exercise tolerance and only laboratory tests could detect factors limiting exercise capacity. It is very likely that an active lifestyle is beneficial for higher exercise capacity values, however it cannot be excluded that better $\mathrm{V}^{\prime} \mathrm{O}_{2}$ max also influences $\mathrm{PA}$ traducing into positive attitudes towards exercise participation $[3,28]$. Thus, one of the limitation recognised in this study is the limited sample size, however, in a specific cohort such as this, recruiting large number in few months can be difficult. In addition, our findings may be limited to some extent by the fact that the study participants were not randomly selected and therefore the study population might be considered as a convenience sample.

\section{Conclusions}

This is the first multicentre study to provide information toward PA attitude in Italian CF adolescent population. PA is an important factor in growth and development of children, and maintaining high levels of PA is important in the management of CF. Published data emphasize the importance of any intervention promoting positive attitudes toward exercise while increasing habitual PA in adolescent population. The present study showed that exercise tolerance and levels of PA measured by HAES were not related in Italian adolescents, but the results were difficult to interpret because of intrinsic limitations of the study.

Further studies are needed to find an agreement on the optimal methods of reporting objective PA data and cut-offs for categorising PA intensity in Italian adolescents with CF.

\section{References}

1. Radtke T, Nolan SJ, Hebestreit $H$, Kriemler S (2015) Physical exercise training for cystic fibrosis. Cochrane Database Syst Rev 6: CD002768.

2. Jantzen A, Opoku-Pare M, Bieli C, Ruf K, Hebestreit H, et al. (2016) Perspective on cystic fibrosis and physical activity: Is there a difference compared to healthy individuals? Pediatr Pulmonol 51: 1020-1030.

3. Nixon PA, Orenstein DM, Kelsey SF, Doershuk CF (1992) The prognostic value 
Citation: Cazzarolli C, Tridello G, Tartali C, Meneghelli I, Antonietta Ciciretti IM, et al. (2017) Physical Activity Levels and Performance in Italian Adolescents with Cystic Fibrosis: A Multicenter Cross-sectional Study. J Pulm Respir Med 7: 430. doi: 10.4172/2161-105X.1000430

Page 5 of 5

of exercise testing in subjects with cystic fibrosis. N Engl J Med 327: 17851788.

4. Cox NS, Alison JA, Button BM, Wilson JW, Morton JM, et al. (2016) Physical activity participation by adults with cystic fibrosis: An observational study. Respirology 21: 511-518.

5. Tejero S, Cejudo P, Quintana-Gallego E, Sañudo B, Oliva-Pascual-Vaca A (2016) The role of daily physical activity and nutritional status on bone turnover in cystic fibrosis: a cross-sectional study. Braz J Phys Ther 20: 206-212.

6. Selvadurai HC, Blimkie CJ, Cooper PJ, Mellis CM, Van Asperen PP (2004) Gender differences in habitual activity in children with cystic fibrosis. Arch Dis Child 89: 928-933.

7. Schneiderman JE, Wilkes DL, Atenafu EG, Nguyen T, Wells GD, et al. (2014) Longitudinal relationship between physical activity and lung health in subjects with cystic fibrosis. Eur Respir J 43: 817-823.

8. Williams CA, Stevens D (2013) Physical activity and exercise training in young people with cystic fibrosis: Current recommendations and evidence.

9. Nixon PA, Orenstein DM, Kelsey SF (2001) Habitual physical activity in children and adolescents with cystic fibrosis. Med Sci Sports Exerc 33: 30-35.

10. Aznar S, Gallardo C, Fiuza-Luces C, Santana-Sosa E, López-Mojares LM, et al. (2014) Levels of moderate--vigorous physical activity are low in Spanish children with cystic fibrosis: A comparison with healthy controls. J Cyst Fibros 13: $335-340$

11. Rasekaba TM, Button BM, Wilson JW, Holland AE (2013) Reduced physical activity associated with work and transport in adults with cystic fibrosis. J Cyst Fibros 12: 229-233.

12. WHO (2010) Global recommendations on physical activity for health.

13. Britto MT, Garrett JM, Konrad TR, Majure JM, Leigh MW (2000) Comparison of physical activity in adolescents with cystic fibrosis versus age-matched controls. Pediatr Pulmonol 30: 86-91.

14. Centers for Disease Control and Prevention.

15. Standardization of spirometry, 1994 update. American Thoracic Society. Am J Respire Crit Care Med 152: 1107-1136.

16. Wells GD, Wilkes DL, Schneiderman-Walker J, Elmi M, Tullis E, et al. (2008) Reliability and validity of the habitual activity estimation scale (HAES) in subjects with cystic fibrosis. Pediatr Pulmonol 43: 345-3 53

17. Selvadurai HC, Cooper PJ, Meyers N, Blimkie CJ, Smith L, et al. (2003) Validation of shuttle tests in children with cystic fibrosis. Pediatr Pulmonol 35 133-138.
18. Rovedder PM, Flores J, Ziegler B, Casarotto F, Jaques P, et al (2014) Exercise programme in subjects with cystic fibrosis: A randomized controlled trial. Respir Med 108: 1134-1140.

19. ACSM'S (2000) Guidelines for exercise testing and prescription.

20. Monti F, Lupi F, Gobbi F, Agostini F, Miano A, et al. (2008) Validation of the Italian version of the Cystic Fibrosis Quality of Life Questionnaire (CFQoL), a disease specific measure for adults and adolescents with cystic fibrosis. J Cyst Fibros 7: 116-122.

21. Bradley J, Howard J, Wallace E, Elborn S (2000) Reliability, repeatability, and sensitivity of the modified shuttle test in adult cystic fibrosis. Chest 117: 16661671.

22. Savi D, Quattrucci S, Internullo M, De Biase RV, Calverley PM, et al. (2013) Measuring habitual physical activity in adults with cystic fibrosis. Respir Med 107: $1888-1894$

23. Selvadurai HC, Allen J, Sachinwalla T, Macauley J, Blimkie CJ, et al. (2003) Muscle function and resting energy expenditure in female athletes with cystic fibrosis. Am J Respir Crit Care Med 168: 1476-1480.

24. Kilbride E, Widger J, Hussey J, E Nazir B, Greally P (2012) Exercise capacity in prepubertal children with cystic fibrosis.

25. Troosters T, Langer D, Vrijsen B, Segers J, Wouters K, et al. (2009) Skeletal muscle weakness, exercise tolerance and physical activity in adults with cystic fibrosis. Eur Respir J 33: 99-106.

26. Alison JA, Regnis JA, Donnelly PM, Adams RD, Sutton JR, et al. (1997) Evaluation of supported upper limb exercise capacity in subjects with cystic fibrosis. Am J Respir Crit Care Med 156: 1541-1548.

27. Dourado VZ, Antunes LC, Tanni SE, de Paiva SA, Padovani CR, et al (2006) Relationship of upper-limb and thoracic muscle strength to 6-min walk distance in COPD subjects. Chest 129: 551-557.

28. Hebestreit A, Kersting U, Basler B, Jeschke R, Hebestreit H (2001) Exercise inhibits epithelial sodium channels in subjects with cystic fibrosis. Am J Respir Crit Care Med 164: 443-446.

29. Hommerding PX, Baptista RR, Makarewicz GT, Schindel CS, Donadio MV, et al. (2015) Effects of an educational intervention of physical activity for children and adolescents with cystic fibrosis: A randomized controlled trial. Respir Care 60: $81-87$

30. Bradley J, O'Neill B, Kent L, Hulzebos EH, Arets B, et al. (2015) Physical activity assessment in cystic fibrosis: A position statement. J Cyst Fibros 14: e25-32. 